\title{
Cellular Mechanisms Associated with Spontaneous and Ciliary Neurotrophic Factor-cAMP-Induced Survival and Axonal Regeneration of Adult Retinal Ganglion Cells
}

\author{
Kevin Park, ${ }^{1}$ Jian-Min Luo, ${ }^{2}$ Susan Hisheh, ${ }^{1}$ Alan R. Harvey, ${ }^{1}$ and Qi Cuii ${ }^{1,2}$ \\ ${ }^{1}$ School of Anatomy and Human Biology and Western Australian Institute for Medical Research, The University of Western Australia, Crawley, Perth WA \\ 6009, Australia, and 2Laboratory for Neural Repair, Shantou University Medical College, Shantou 515031, People's Republic of China
}

We have shown previously that intraocular elevation of cAMP using the cAMP analog 8-(4-chlorophenylthio)-cAMP (CPT-cAMP) failed to promote axonal regeneration of axotomized adult retinal ganglion cells (RGCs) into peripheral nerve (PN) grafts but significantly potentiated ciliary neurotrophic factor (CNTF)-induced axonal regeneration. Using the PN graft model, we now examine the mechanisms underlying spontaneous and CNTF/CPT-cAMP-induced neuronal survival and axonal regrowth. We found that blockade of the cAMP pathway executor protein kinase A (PKA) using the cell-permeable inhibitor KT5720 did not affect spontaneous survival and axonal regeneration but essentially abolished the CNTF/CPT-cAMP-induced RGC survival and axonal regeneration. Blockade of CNTF signaling pathways such as phosphotidylinositol 3-kinase (PI3K)/akt by 2-(4-morpholinyl)-8-phenyl-4H-1-benzopyran-4-one (LY294002), mitogen-activated protein kinase (MAPK)/extracellular signal-regulated kinase (ERK) by 2-(2-diamino-3-methoxyphenyl-4H-1benzopyran-4-one (PD98059), or Janus kinase (JAK)/signal transducer and activators of transcription (STAT3) by tyrphostin AG490 also blocked the CNTF/CPT-cAMP-dependent survival and regeneration effects. PKA activity assay and Western blots showed that KT5720, LY294002, and PD98059 almost completely inhibited PKA, PI3K/akt, and MAPK/ERK signal transduction, respectively, whereas AG490 substantially decreased JAK/STAT3 signal transduction. Intraocular injection of CPT-cAMP resulted in a small PKA-dependent increase in CNTF receptor $\alpha$ mRNA expression in the retinas, an effect that may facilitate CNTF action on survival and axonal regeneration. Surprisingly, in the absence of CNTF/CPT-cAMP, LY294002, PD98059, and AG490, but not KT5720, significantly enhanced spontaneous RGC survival, suggesting differential roles of these pathways in RGC survival under different conditions. Our data suggest that CNTF/ CPT-cAMP-induced RGC survival and axonal regeneration are a result of multiple pathway actions, with PKA as an essential component, but that these pathways can function in an antagonistic manner under different conditions.

Key words: ciliary neurotrophic factor; cAMP; protein kinase A; phosphotidylinositol 3-kinase; mitogen-activated protein kinase; Janus kinase

\section{Introduction}

cAMP plays an important role in diverse neuronal functions including survival (Rydel and Greene, 1988; Hanson et al., 1998), modulation of axonal guidance (Ming et al., 1997; Nishiyama et al., 2003), and enhancement of neurite outgrowth (Jo et al., 1999; Kao et al., 2002). Recently, cAMP elevation was also shown to promote the regeneration of dorsal root ganglion axons into spinal cord (Neumann et al., 2002; Qiu et al., 2002). We reported recently that intraocular injection of ciliary neurotrophic factor (CNTF) increased the regeneration of adult retinal ganglion cell (RGC) axons into peripheral nerve (PN) grafts in vivo (Cui et al., 1999), and intraocular cAMP elevation using the cAMP analog

Received Sept. 2, 2004; revised 0ct. 10, 2004; accepted 0ct. 11, 2004.

This work was supported by grants from the Australian National Health and Medical Research Council to Q.C. and A.R.H. (211924 and 990067), the Western Australia Neurotrauma Research Program, and Shantou University Medical College and was partially supported by The National Key Basic Research Program of China (2003CB515303).

Correspondence should be addressed to Dr. Qi Cui, School of Anatomy and Human Biology, The University of Western Australia, 35 Stirling Highway, Crawley, Perth WA 6009, Australia. E-mail: cuiqi@anhb.uwa.edu.au.

DOI:10.1523/JNEUROSCI.3532-04.2004

Copyright $\odot 2004$ Society for Neuroscience ～0270-6474/04/2410806-10\$15.00/0
8-(4-chlorophenylthio)-cAMP (CPT-cAMP) significantly potentiated the CNTF-induced axonal regeneration of RGCs (Cui et al., 2003). Similarly, cAMP elevation and neurotrophin-3 application have a synergistic effect on axonal regeneration in spinal cord (Lu et al., 2004).

cAMP acts on protein kinase A (PKA) to exert many of its biological functions (Li et al., 2000), effects that are blocked by the cell-permeable PKA inhibitor KT5720 (Qiu et al., 2002). In vitro, KT5720 has also been reported to influence other signaling pathways such as mitogen-activated protein kinase (MAPK)/extracellular signal-related kinase (ERK) and akt (Davies et al., 2000). CNTF elicits its primary biological actions via the Janus kinase (JAK)/signal transducer and activators of transcription (STAT3), phosphatidylinositol 3-kinase (PI3K)/akt, and MAPK/ ERK pathways (Ip and Yancopoulos, 1996; Peterson et al., 2000; Alonzi et al., 2001; Dolcet et al., 2001; Goldberg et al., 2002; Guillet et al., 2002; Kaur et al., 2002). PI3K/akt plays an important role in mediating the survival of certain neurons (Vaillant et al., 1999; Namikawa et al., 2000; Campos et al., 2003), whereas the MAPK/ERK pathway has no influence (Vaillant et al., 1999; 
Namikawa et al., 2000; Alonzi et al., 2001) or a more minor influence (Mazzoni et al., 1999; Atwal et al., 2000) on cell viability. Nevertheless, both the PI3K/akt and MAPK/ERK pathways are involved in axonal regeneration in vivo and neurite outgrowth in vitro (Cowley et al., 1994; Miura et al., 1994; Namikawa et al., 2000; Desbarats et al., 2003).

The aim of the present study, using the PN-to-optic nerve (ON) approach in adult rats, was to elucidate the mechanisms underlying both spontaneous and CNTF/cAMP elevation-induced RGC survival and axonal regeneration. We injected intraocularly the PKA pathway inhibitor KT5720, the PI3K/akt pathway inhibitor 2-(4morpholinyl)-8-phenyl-4H-1-benzopyran-4-one (LY294002), the MAPK/ERK pathway inhibitor 2-(2-diamino-3-methoxyphenyl-4H1-benzopyran-4-one (PD98059), or the JAK/STAT3 pathway inhibitor AG490, a member of the tyrphostin family of protein kinase inhibitors (Sanchez-Margalet et al., 1994; Alessi et al., 1995; Dolcet et al., 2001; Goldberg et al., 2002). Using quantitative methods, we then determined whether inhibition of these pathways influenced the levels of spontaneous and CNTF/cAMP-induced RGC survival and axonal regeneration into PN grafts. Because cAMP elevation has been reported to upregulate the expression of CNTF receptor $\alpha(\mathrm{CNTFR} \alpha)$, the extracellular binding component of CNTF receptor complex (Ip and Yancopoulos, 1996), in certain neuroglial cells in vitro (Wewetzer et al., 2001), we also examined the effect of cAMP elevation on retinal CNTFR $\alpha$ mRNA expression in this in vivo regeneration model.

\section{Materials and Methods}

Young adult ( $8-10$ weeks of age) Fischer 344 rats were used in this study. All surgical procedures were approved by the Animal Ethics Committees of The University of Western Australia and Shantou University Medical College.

Peripheral nerve grafting procedure. The $\mathrm{PN}-\mathrm{ON}$ surgery procedure has been published previously (Cui et al., 1999, 2003; Yin et al., 2003). Briefly, rats were anesthetized with a $1: 1$ mixture $(1.5 \mathrm{ml} / \mathrm{kg})$ of ketamine $(100$ $\mathrm{mg} / \mathrm{ml})$ and xylazine $(20 \mathrm{mg} / \mathrm{ml})$. The left $\mathrm{ON}$ was exposed intraorbitally and transected within the sheath $\sim 1.5 \mathrm{~mm}$ behind the optic disc. To preserve the retinal blood supply, care was taken not to damage the underlying ophthalmic artery. A $1.5 \mathrm{~cm}$ piece of peroneal nerve was dissected out from the left leg and sutured with 10/0 suture (Johnson and Johnson, North Ryde, Australia) onto the proximal stump of the transected ON. The distal part of the PN was placed over the skull and secured to connective tissue.

Experimental groups. PN-grafted animals were allocated to different experimental groups. The first group received no intravitreal injections, and the second group received intravitreal injections of saline; both groups served as controls. The rest of the animals received intravitreal injections of rat recombinant CNTF ( $1.5 \mu \mathrm{g}$ per injection; PeproTech, Rehovot, Israel), the cell-permeable cAMP analog CPT-cAMP (0.1 mM; Sigma, St. Louis, MO), the PKA pathway inhibitor KT5720 (10 $\mu \mathrm{M}$; Sigma), the PI3K/akt pathway inhibitor LY294002 (2 mM; Sigma), the MAPK/ERK pathway inhibitor PD98059 (5 mm; Sigma), or the JAK/ STAT3 pathway inhibitor AG490 (2 mm; Calbiochem, La Jolla, CA) alone or in various combinations (see Fig. 1). For intravitreal injections, all rats received three posterior chamber eye injections of various molecules, $3 \mu \mathrm{l}$ each, on days 3, 10, and 17 after PN-ON surgery (see Fig. 1). For each intravitreal injection, the micropipette was inserted in peripheral retina, just behind the ora serrata, and was deliberately angled to avoid damage to the lens (Leon et al., 2000).

Retrograde labeling of $R G C s$ with regenerating axons. The fastestregenerating RGC axons grow in PN grafts at a rate of $\sim 2 \mathrm{~mm} / \mathrm{d}$, after an initial delay period of $4-5 \mathrm{~d}$ (Cho and So, 1987). To provide sufficient time for regrowing axons to reach the distal end of the PN grafts, the number of RGCs with regenerating axons was assessed 1 month after surgery. To retrogradely label these regenerating RGC axons and their parent cell bodies, $0.2 \mu \mathrm{l}$ of $4 \%$ fluorogold (FG) (Fluorochrome, Denver, $\mathrm{CO})$ was injected slowly into the distal end of the PN graft. Animals survived for another $3 \mathrm{~d}$ to maximize retrograde transport of the dye. After deeply anesthetizing the animals with sodium pentobarbitone (Nembutal, $60 \mathrm{mg} / \mathrm{ml}$, i.p.; Merial Australia, Parramatta, Australia), the rats were perfused with $4 \%$ paraformaldehyde in phosphate buffer $(0.1$ $\mathrm{M}, \mathrm{pH}$ 7.4). Injection of a small volume of FG was essential to avoid diffusion of dye toward the optic disc and consequent staining of viable but non-axon-regenerating RGCs (Cui et al., 2003).

After removal from the eye cups, retinas were postfixed in $4 \%$ paraformaldehyde for $45 \mathrm{~min}$, flat mounted, and temporarily coverslipped in Citifluor (Citifluor, London, UK). To determine the total number of FG-labeled RGCs, the outline of each retina was drawn on a computer screen using an MD2 microscope digitizer (Accustage, Shoreview, MN), and a grid was randomly placed over the drawing. A cursor was placed on each grid intersection, and the number of FG-labeled RGCs was counted at that point. Each sample field was $0.235 \times 0.235 \mathrm{~mm}$, and $60-80$ fields were sampled per retina (Cui et al., 2003). The average number per field of RGCs with regenerating axons was determined, and the total FGlabeled RGC number was then obtained by multiplying this figure by the retinal area.

Immunohistochemical staining of viable RGCs. After FG counts were made, whole retinas were immunostained with an antibody to neuronal class $\beta$ III tubulin (TUJ1; Babco, Richmond, CA). TUJ1 staining in retinal whole mounts was shown to be adult RGC specific and was efficient in RGC identification (Cui et al., 2003; Yin et al., 2003). Coverslips were removed, and retinas were brushed off the slides in PBS. After PBS washes, retinas were blocked in $10 \%$ normal goat serum (Hunter Antisera, Jesmond, Australia) and 0.2\% Triton X-100 (Sigma) for $1 \mathrm{hr}$ and then incubated in the same medium with TUJ1 antibody (1:500) for $1 \mathrm{~d}$ at $4^{\circ} \mathrm{C}$. After additional washes, retinas were incubated with cyanine 3 -conjugated goat anti-mouse IgG (1:100; The Jackson Laboratory, Bar Harbor, ME) overnight at $4^{\circ} \mathrm{C}$. Retinas were again flat mounted onto slides and coverslipped in Citifluor. The number of TUJ1immunofluorescent cells in the ganglion cell layer was calculated using the sampling procedures described above for FG labeling.

cAMP-dependent protein kinase A activity assay. The effectiveness of intraocular KT5720 injection in blocking PKA activity was examined using the PepTag assay for nonradioactive detection of cAMP-dependent protein kinase (Promega, Madison, WI). The procedure was performed following the manufacturer's protocol.

Briefly, $3 \mathrm{~d}$ after $\mathrm{PN}-\mathrm{ON}$ procedure, eyes were injected with saline $(n=3)$, a mixture of CNTF and CPT-cAMP $(n=3)$, or a mixture of CNTF, CPT-cAMP, and KT5720 $(n=4)$. Animals were allowed to survive for another $6 \mathrm{hr}$. Normal intact animals $(n=3)$ were used as controls. Total protein from retina was extracted with lysis buffer ( $1 \%$ Triton $\mathrm{X}-100,0.5 \%$ NP-40, 1 mм EDTA, $150 \mathrm{~mm} \mathrm{NaCl}, 1 \mathrm{~mm}$ PMSF, $5 \mathrm{~mm}$ sodium pyrophosphate, $0.2 \mathrm{~mm}$ sodium molybdate, $0.05 \mathrm{~mm}$ sodium fluoride, and $1 \mathrm{~mm}$ sodium orthovanadate), and cell supernatant was collected after centrifuging at 15,000 $\times \mathrm{g}$ for $15 \mathrm{~min}$, snap frozen, and kept at $-80^{\circ} \mathrm{C}$ for later usage. For each sample, $5 \mu \mathrm{l}$ of reaction buffer, $\mathrm{A} 1$ peptide (PKA substrate kemptide), and $1 \mu$ l of peptide protection solution were added, and the mixture was incubated at room temperature for $30 \mathrm{~min}$. The reaction was stopped by placing the tube in a $95^{\circ} \mathrm{C}$ heating block for $10 \mathrm{~min}$. The phosphorylated (phospho)-PKA downstream products (phospho-kemptide) were separated from unphosphorylated kemptide (unphospho-kemptide) in a $0.8 \%$ agarose gel, and bands were visualized under UV light. The gel was photographed and quantified using ScionImage (Scion, Frederick, MD) densitometric software.

Western blot analysis to confirm pathway inhibition. Western blot experiments were used to determine the efficacy of the intraocular LY294002, PD98059, and AG490 injections in inhibiting PI3K/akt, MAPK/ERK, and JAK/STAT3 pathways, respectively. We examined the levels of downstream products of these pathways: phospho-Akt in the PI3K/akt pathway, phospho-ERK1/2 in the MAPK/ERK pathway, and phospho-STAT3 in the JAK/STAT3 pathway. The levels of these products were determined at both $6 \mathrm{hr}$ and $3 \mathrm{~d}$ after the intraocular injections of the inhibitors, which in turn had been injected $3 \mathrm{~d}$ after the PN graft procedure.

Retinas were homogenized using the same lysis buffer as above. The protein concentration of the supernatant was determined using the Bio- 
Rad (Hercules, CA) protein assay reagent. Approximately $50 \mu \mathrm{g}$ of protein was loaded and separated in a $10 \%$ acrylamide-Bis solution (Bio$\mathrm{Rad})$ gel. The protein was transferred onto Hybond-C Super membrane (Amersham Biosciences, Little Chalfont, UK) and blocked with 5\% skim milk in $0.1 \%$ Tween 20 (ICN Biochemicals, Cleveland, OH) in TBS (TTBS). The membranes were incubated with phosphorylated or unphosphorylated primary anti-akt (1:1000), anti-ERK1/2 (1:2000 for phosphorylated and 1:1000 for unphosphorylated), or anti-STAT3 (1:1000) antibodies (all from Cell Signaling, Beverly, MA, except phospho-ERK1/2 antibody, which is from Promega) in 5\% BSA in TTBS overnight at $4^{\circ} \mathrm{C}$. After washing in TTBS, the membranes were incubated in biotinylated secondary antibody (Vector Laboratories, Burlingame, $\mathrm{CA}$ ) at a 1:20,000 dilution for $1 \mathrm{hr}$ at room temperature. The membranes were incubated with HRP-conjugated antibody (Babco) before the labeled proteins were detected using the ECL agent (Pierce, Rockford, IL), following the supplier's manual. Membranes were then exposed to Kodak (Rochester, NY) X-Omat AR film, and the images on the film were developed with Kodak film developer and fixed with Ilford fixer (Ilford, Mt. Waverley, Australia). Membranes were stripped by incubating them with stripping buffer ( $2 \%$ SDS, $7 \mu \mathrm{l}$ of $\beta$-mercaptoethanol $/ \mathrm{ml}$ in TTBS, $\mathrm{pH}$ 7.6) at room temperature for $30 \mathrm{~min}$ followed by two brief washes with TTBS. Membranes were then blocked again in 5\% skim milk in TTBS before reprobing them with antibodies against unphospho-akt, against unphospho-ERK1/2, or against unphospho-STAT3 or monoclonal anti- $\beta$-actin antibody (Sigma), which was used as loading control. The antibodies were diluted 1:1000 in 5\% BSA-TTBS. The intensity of each band was quantified using the ScionImage program. The relative levels of phospho-Akt, ERK1/2, and STAT3 were expressed as the ratio to $\beta$-actin.

Western blot analysis to examine whether cross-talk exits between PI3K/ akt, MAPK/ERK, and JAK/STAT3 pathways. In PN-ON-only animals, RGC survival was increased after inhibition of the PI3K/akt, MAPK/ ERK, or JAK/STAT3 pathways. It was possible that inhibition of one of these pathways led to increased activity in one of the other signaling cascades. Thus, we further investigated whether cross-talk exists between these affected signaling pathways. Using the same surgical and Western blot approaches described above, we measured PI3K/akt pathway activity after application of PD98059 and AG490, MAPK/ERK pathway activity after application of LY294002 and AG490, and JAK/STAT3 pathway activity after application of LY294002 and PD98059.

Reverse transcription and quantitative PCR study for CNTFR $\alpha$ expression. To investigate the effect of cAMP elevation on CNTFR $\alpha$ mRNA expression in retina, real-time PCR was used to examine the level of CNTFR $\alpha$ mRNA expression after certain treatments.

The surgical procedures were the same as above but with different intravitreal treatments. Briefly, $3 \mathrm{~d}$ after the $\mathrm{PN}-\mathrm{ON}$ procedure, we performed intravitreal injections of saline, CNTF, CPT-cAMP at various concentrations, or combined application of CPT-cAMP and KT5720 in a $3 \mu \mathrm{l}$ volume. There were four to five animals in each group, and all animals survived for another $3 \mathrm{~d}$. After killing animals with a Nembutal overdose, the retinas were quickly dissected out and immediately put into RNAlater (Ambion, Austin, TX). They were stored at $4^{\circ} \mathrm{C}$ until processing. PCR procedures were then performed by an independent researcher (S.H.) who did not know the origin of the samples. RNA was isolated from each retina using $1 \mathrm{ml}$ of RNAwiz (Ambion), and equal amounts of total RNA $(1 \mu \mathrm{g})$ were reverse transcribed in $25 \mu \mathrm{l}$ volumes with Moloney murine leukemia virus reverse transcriptase (RT) (Promega) and random hexamers (Promega), according to manufacturer's instructions. The reactions were then purified through columns (MoBio PCR Clean-up; MoBio Laboratories, West Carlsbad, CA) before quantitative PCR. Quantitative PCR was performed using the Roche (Basel, Switzerland) LightCycler with the following primers: CNTFR $\alpha$ (forward, 5'-AAGCCCGATCCTCCAGAAAATGTG-3'; reverse, 5' -CTCCATGTCCCAATCTCATTGTCC-3') as described by Wewetzer et al. (2001) and L19 ribosomal protein RNA (forward, 5'-CTGAAGGTCAAAGGGAATGTG-3; reverse, 5'-GGACAGAGTCTTGATGATCTC- $3^{\prime}$ ). Reactions were performed using $1 \mu \mathrm{l}$ of FastStart DNA Master SYBR Green I (Roche) with $2 \mathrm{mM} \mathrm{MgCl}_{2}, 0.5 \mu \mathrm{M}$ primers (CNTFR $\alpha$ ) or with $3 \mathrm{~mm} \mathrm{MgCl}_{2}, 0.5 \mu \mathrm{M}$ primers (L19) in a total volume of $10 \mu \mathrm{l}$. Cycling conditions were: $95^{\circ} \mathrm{C}$ for $15 \mathrm{sec}, 52^{\circ} \mathrm{C}$ for $5 \mathrm{sec}$, and
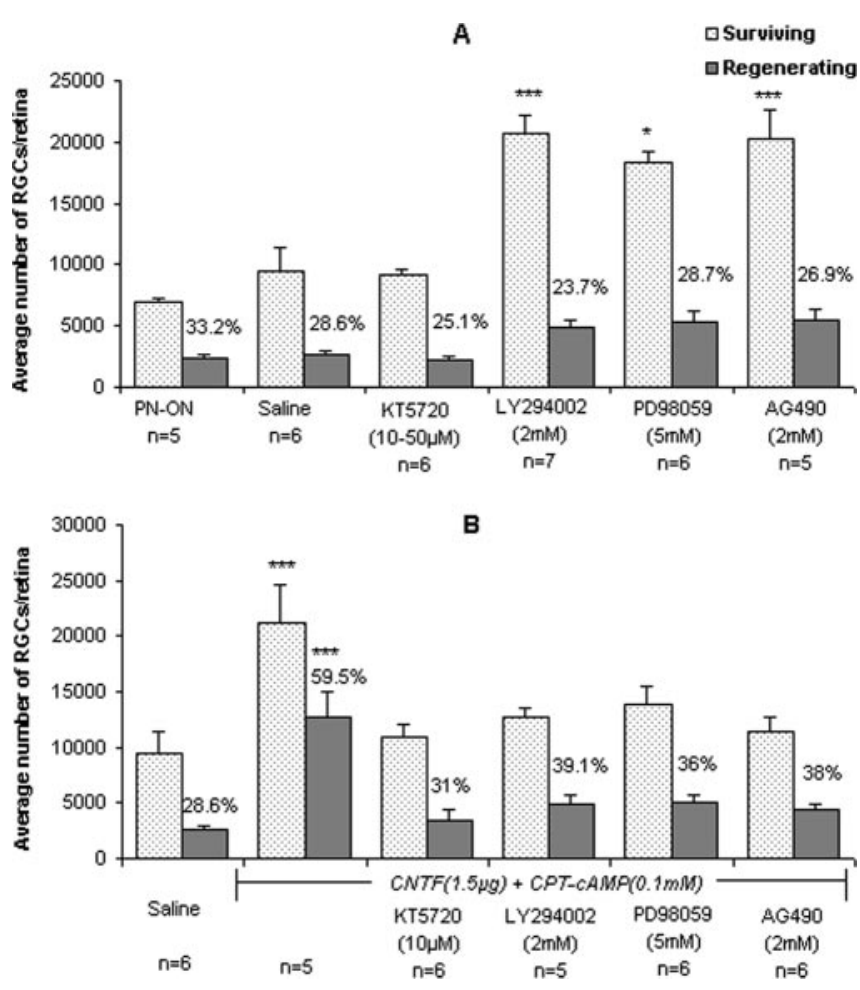

Figure 1. Average numbers of FG-labeled axon-regenerating and TUJ1-positive surviving $\mathrm{RGCS}$ under various experimental conditions in the absence $(A)$ or presence $(B)$ of CNTF/CPTCAMP. ${ }^{*} p<0.05,{ }^{* * *} p<0.001$; Dunnett's test; comparisons were made against the saline group. Error bars represent SEM.

$72^{\circ} \mathrm{C}$ for $10 \mathrm{sec}$ for $45 \mathrm{cycles}(\mathrm{CNTFR} \alpha)$ and $95^{\circ} \mathrm{C}$ for $15 \mathrm{sec}, 52^{\circ} \mathrm{C}$ for 5 sec, and $72^{\circ} \mathrm{C}$ for $8 \mathrm{sec}$ for 45 cycles (L19). Controls (with and without RT enzyme) were used to check for genomic DNA amplification.

Statistical analysis. RGC data from the different groups were statistically analyzed using Dunnett's or Bonferroni tests after one-way ANOVA. Dunnett's test was used to compare mean values of experimental groups against the same control group (usually the saline treatment group), whereas the Bonferroni test was used to compare mean values among all intragroups. Both procedures have been used widely (Cui et al., 2003; Yin et al., 2003; Pearse et al., 2004).

\section{Results}

One month after the $\mathrm{PN}-\mathrm{ON}$ procedure, the average numbers of surviving (TUJ1-positive) and axon-regenerating (FG-positive) RGCs were $6910 \pm 277$ (mean \pm SEM) per retina and $2297 \pm 323$ $($ mean \pm SEM $)$ per retina in the $\mathrm{PN}-\mathrm{ON}$-only group and $9398 \pm$ 2048 per retina and $2685 \pm 328$ per retina in the $\mathrm{PN}-\mathrm{ON}$ plus intraocular injection of saline group, respectively (Fig. $1 A$ ). For comparison, note that there are $\sim 110,000$ RGCs per retina in normal adult Sprague Dawley rats (Cui et al., 2003). Intravitreal saline injections slightly increased both RGC survival and axonal regeneration; however, these increases were not significant. Examples of surviving and axon-regenerating RGCs are shown in Figure 2.

\section{PKA pathway in spontaneous and CNTF/CPT-cAMP-induced RGC survival and axonal regeneration \\ PKA activity assays}

PKA activity assays (Fig. $3 A$ ) and quantitative analysis of the results (Fig. $3 B$ ) showed that the $\mathrm{PN}-\mathrm{ON}$ procedure and intravitreal injection of saline substantially reduced PKA activity in the affected eyes compared with the normalized level in intact animals. Intraocular injection of CNTF and CPT-cAMP signifi- 


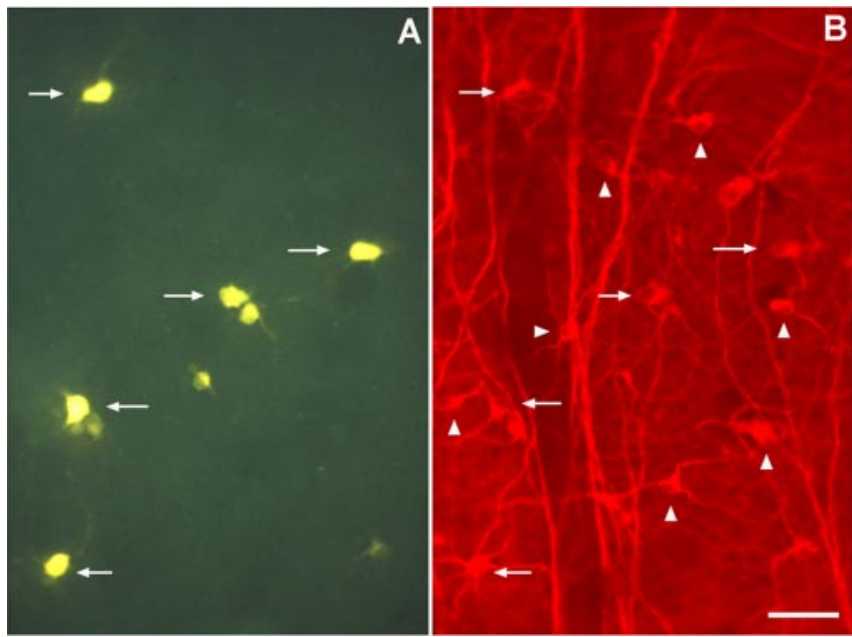

Figure 2. Fluorescent photomicrographs of a retinal whole mount showing characteristics of retrogradely FG-labeled RGCs that have regenerated an axon into a PN graft ( $A$, arrows) and surviving TUJ1-immunoreactive RGCS $(B)$. $A$ and $B$ are the same retinal field but using different fluorescent filters. FG-labeled RGCs are clearly also TUJ1 positive ( $B$, arrows); however, many of the TUJ1-positive RGCs do not contain FG (arrowheads); they are therefore viable but do not have axons regenerating to the distal end of the PN graft. Scale bar, $50 \mu \mathrm{m}$.

A

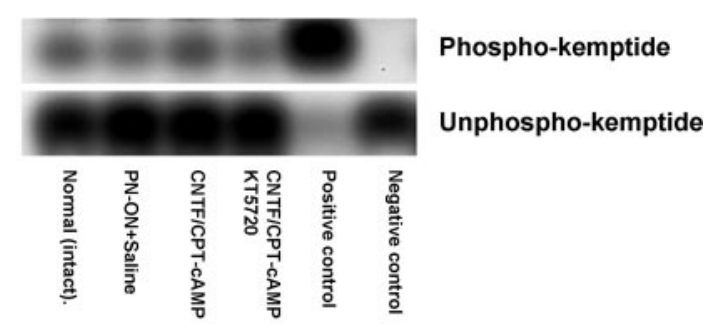

B PKA activity indicated by pathway downstream product phospho-kemptide under various intraocular conditions

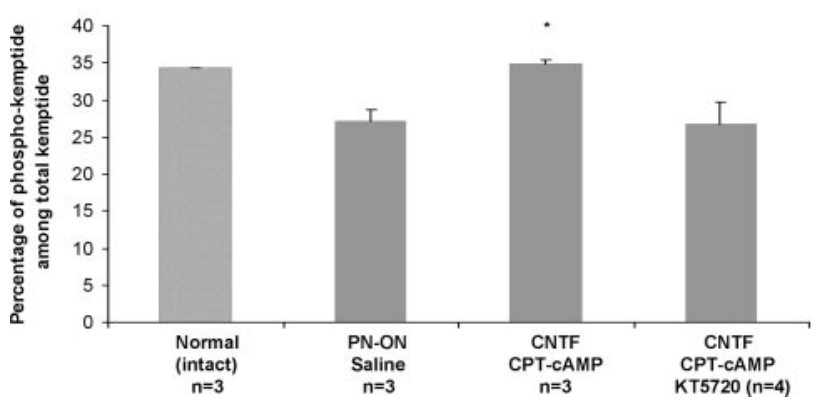

Figure 3. PKA activity assay $(A)$ and quantitative analysis of the results $(B)$. $A$, The top row shows the level of phosphorylated kemptide, a downstream PKA pathway product, whereas the bottom row depicts unphosphorylated kemptide. $B$, Proportions of phosphorylated kemptide among total kemptide. Intraocular injection of $3 \mu$ l of the PKA pathway inhibitor KT5720 at $10 \mu$ m effectively blocked PKA signaling activity in the retina. Error bars in $B$ represent SEM; ${ }^{*} p<0.05$.

cantly ( $p<0.05$; Dunnett's test) increased PKA activity in PNgrafted rats, returning PKA levels to those seen in unoperated animals. This CNTF- and CPT-cAMP-induced increase in PKA activity was completely blocked by the PKA pathway inhibitor KT5720 at $10 \mu \mathrm{M}$ (Fig. 3), and the level of PKA activity appeared to be even lower than in the saline group, confirming that KT5720 was efficient in inhibiting the PKA pathway at this concentration in this in vivo adult CNS model.

\section{$R G C$ counts}

Intraocular injections of KT5720 alone did not affect spontaneous survival and axonal regeneration of RGCs after the PN-ON procedure. Compared with the intraocular saline-injected group, the average number of both surviving (9107 \pm 541 per retina) and axon-regenerating (2284 \pm 304 per retina) RGCs in the KT5720 treatment group was not significantly different (Fig. 1A).

Compared with the $\mathrm{PN}-\mathrm{ON}$ control and saline injection groups, combined intraocular injections of CNTF and the cAMP analog CPT-cAMP significantly increased the number of surviving $(21,273 \pm 3411$ per retina; $p<0.001)$ and axon-regenerating $(12,661 \pm 2385$ per retina; $p<0.001)$ RGCs (Fig. $1 B)$. Relating these values to the total number of RGCs in normal unlesioned retinas, with CNTF/cAMP treatment, approximately one in five adult rat RGCs survived for at least 4 weeks after the PN-ON surgery, and of these, $\sim 60 \%$ had regenerated axons into PN grafts. In contrast, the proportion of regenerating-to-surviving RGCs was $33.2 \%$ in the $\mathrm{PN}-\mathrm{ON}$ group with no eye injections and $28.6 \%$ in the saline-injected group. These data thus confirm our previous finding that CNTF/cAMP promotes the survival of axotomized adult RGCs and significantly increases the proportion of viable RGCs that can regenerate their axons into a PN graft (Cui et al., 2003).

When KT5720 was applied together with CNTF/CPT-cAMP, the increase in CNTF/CPT-cAMP-induced RGC survival and axonal regeneration was almost completely blocked (Fig. $1 \mathrm{~B}$ ). Both the survival $(10,912 \pm 1179$ per retina) and axonal regeneration (3386 \pm 1070 per retina) of RGCs in the CNTF/CPT-cAMP/ KT5720 treatment group were significantly lower $(p<0.01$ for survival and $p<0.001$ for regeneration; Bonferroni) than the CNTF/CPT-cAMP group. Furthermore, these values were not significantly different from the $\mathrm{PN}-\mathrm{ON}$ control or saline injection groups (Fig. 1). Thus, in contrast to spontaneous survival and axonal regrowth, the PKA pathway plays a critical role in CNTF/CPT-cAMP-induced survival and axonal regeneration of adult rat RGCs.

\section{PI3K/akt pathway in spontaneous and CNTF/CPT-cAMP- induced RGC survival and axonal regeneration}

\section{Western blots}

Western blot analysis revealed slightly different results $6 \mathrm{hr}$ or $3 \mathrm{~d}$ after intravitreal injection of the various molecules or combinations of molecules (Fig. 4). Compared with normal (intact) control retinas, the $\mathrm{PN}-\mathrm{ON}$ procedure and intravitreal injection of saline did not render an immediate effect on PI3K activity in the retinas (Fig. $4 A$ ), as determined by the level of phospho-akt, but it did slightly increase PI3K activity at a later stage (3 d) (Fig. $4 B$ ). As expected, intraocular injection of CNTF significantly increased the level of phospho-akt, a downstream product of the PI3K/akt pathway at both the $6 \mathrm{hr}(p<0.05$; Dunnett's test) (Fig. $4 A)$ and $3 \mathrm{~d}(p<0.01$; Dunnett's test) (Fig. $4 B)$ time points. The effect appeared to be gradual, because the levels of phospho-akt were higher at the $3 \mathrm{~d}$ than at the $6 \mathrm{hr}$ time point. However, CPT-cAMP treatment also significantly increased the level of phospho-akt when measured at both $6 \mathrm{hr}$ and $3 \mathrm{~d}$ after injection. In fact, the influence of CPT-cAMP was more obvious at $6 \mathrm{hr}$ ( $p<0.01$; Dunnett's test) than at $3 \mathrm{~d}$ ( $p<0.05$; Dunnett's test). An additional increase, although not statistically significant, was seen at $6 \mathrm{hr}$ when CNTF and CPT-cAMP were applied together (Fig. 4A). Importantly, the CNTF/CPT-cAMP-induced increase in phospho-akt was significantly $(p<0.01$; Bonferroni) (Fig. $4 A$ ) blocked by the PI3K/akt pathway inhibitor LY294002 (2 mM) at $6 \mathrm{hr}$ and completely blocked ( $p<0.001$; Bonferroni) (Fig. $4 B$ ) at the $3 \mathrm{~d}$ time point. 


\section{$R G C$ counts}

In the absence of exogenous CNTF and CPT-cAMP, intravitreal injections of LY294002 substantially increased rather than decreased RGC survival (20,640 \pm 1548 per retina) (Fig. $1 A$ ). The number of TUJ1-positive RGCs was significantly higher than that seen in both the PN-ON control and saline-injected groups $(p<$ 0.001; Bonferroni) (Fig. $1 A$ ). Treatment of LY294002 alone also increased, although not significantly, the average number of RGCs regenerating axons into PN grafts (4882 \pm 645 per retina). The increased axonal regeneration is likely to be a consequence of the increased pool of surviving RGCs, because the proportion of axonregenerating RGCs among surviving RGCs in the LY294002 treatment group $(23.7 \%)$ was similar to the saline group (28.6\%) (Fig. 1A).

In contrast to the above observations, when LY294002 was applied together with CNTF/CPT-cAMP, the CNTF/CPTcAMP-induced RGC survival was effectively blocked. The average number of surviving RGCs in this group was 12,668 \pm 892 per retina, not significantly higher than the saline-injected group (Fig. $1 B$ ). After treatment with LY294002, the level of CNTF/CPT-cAMP-induced axonal regeneration also substantially decreased (4959 \pm 782 per retina). This value was significantly lower $(p<0.001$; Bonferroni) than for the CNTF/CPT-cAMP treatment group (Fig. $1 B$ ). The average number of axon-regenerating RGCs in the CNTF/CPT-cAMP/ LY294002 treatment group was higher than the saline group (2685 \pm 328 per retina), but this difference did not reach significance. Similar amounts of RGC survival and axonal regeneration were seen after application of LY294002 at a lower concentration $(0.5 \mathrm{~mm})$ in the presence of CNTF/CPT-cAMP (data not shown).

\section{MAPK/ERK pathway in spontaneous and CNTF/cAMP- induced RGC survival and axonal regeneration}

Western blots

Western blot analysis of the MAPK/ERK pathway $6 \mathrm{hr}$ and $3 \mathrm{~d}$ after various intravitreal treatments showed that the levels of phospho-ERK1/2, downstream products of the MAPK/ERK pathway, increased in the saline-injected group (Fig. $5 A, B$ ). At the $6 \mathrm{hr}$ time point, this increase in phospho-ERK1 $(p<0.01$; Dunnett's test) and ERK2 ( $p<0.05$; Dunnett's test) after saline injection was significant, whereas at the $3 \mathrm{~d}$ time point, only the increase in phospho-ERK2 was significant $(p<0.05$; Dunnett's test). These data suggest an influential effect of the $\mathrm{PN}-\mathrm{ON}$ procedure and eye injection on MAPK/ERK activity.

After CNTF injection, a significant increase in phospho-ERK1 and -ERK2 was seen 6 hr later (Fig. 5A), an increase that was still evident $3 \mathrm{~d}$ after treatment (Fig. $5 B$ ). CPT-cAMP by itself had a minor effect on ERK phosphorylation at the earlier time point (Fig. 5A). After combined application of CNTF and CPT-cAMP, no clear synergistic effect was seen at either the $6 \mathrm{hr}$ or $3 \mathrm{~d}$ time points (Fig. $5 A, B$ ). The MAPK/ERK pathway inhibitor PD98059
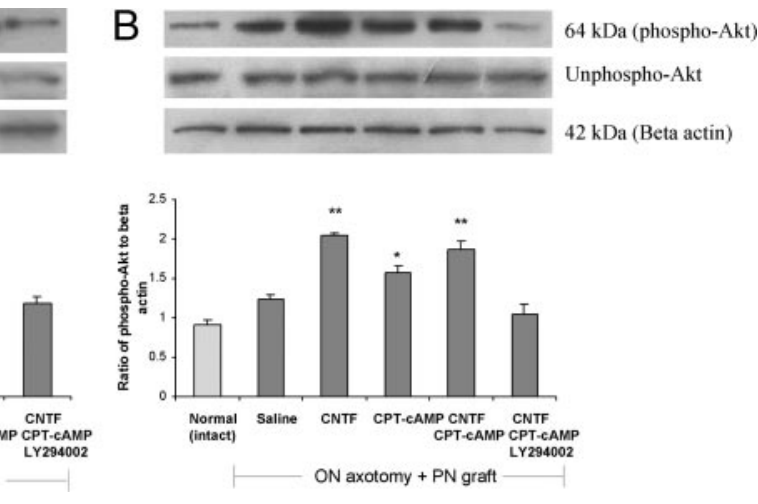

sis on the PI3K pathway downstream product phosphorylated akt $6 \mathrm{hr}(A)$ or $3 \mathrm{~d}(B)$ after various experimental interventions. The PI3K pathway inhibitor LY294002 blocked the CNTF/CPT-CAMP-induced increase in PI3K pathway activity substantially at $6 \mathrm{hr}$ and completely at $3 \mathrm{~d}$ after intravitreal injection. ${ }^{*} p<0.05,{ }^{* *} p<0.01$;
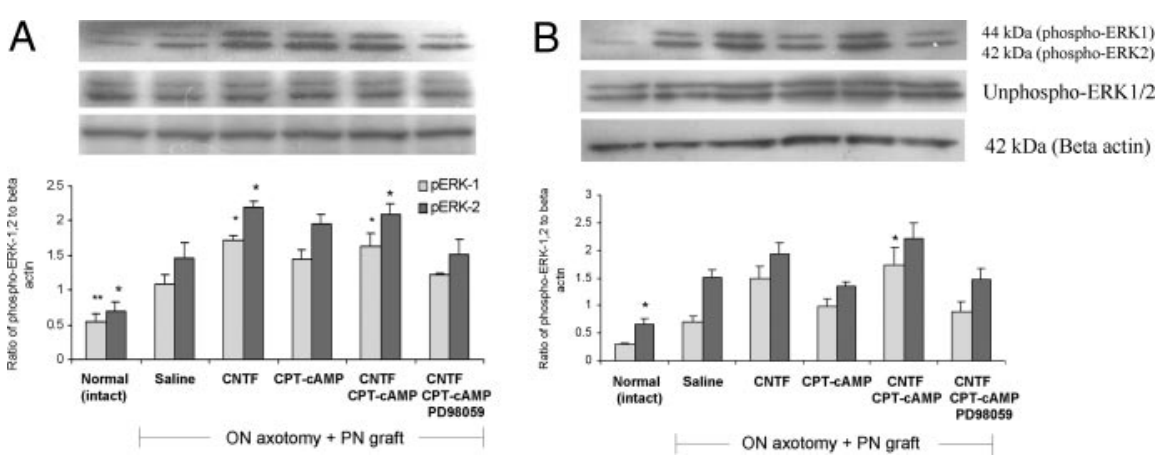

Figure 5. Western blotting study on the MAPK pathway downstream product phosphorylated ERK1/2 $6 \mathrm{hr}(A)$ or $3 \mathrm{~d}(B)$ after various experimental interventions. The MAPK pathway inhibitor PD98059 blocked the CNTF/CPT-CAMP-induced increase in MAPK/ERK pathway activity substantially at $6 \mathrm{hr}$ and completely at $3 \mathrm{~d}$ after intravitreal injection. ${ }^{*} p<0.05,{ }^{* *} p<0.01$; Dunnett's test; comparisons were made against the saline group. Error bars represent SEM.

almost entirely abolished the CNTF- and CPT-cAMP-induced increases in phospho-ERK1 $(p<0.05$ and $p<0.01$ at the $6 \mathrm{hr}$ and $3 \mathrm{~d}$ time points, respectively; Bonferroni) and phosphoERK2 ( $p<0.05$ at the $3 \mathrm{~d}$ time point; Bonferroni), reducing protein expression approximately to the levels seen in the salineinjected group (Fig. 5). These data confirmed the effectiveness of this molecule in inhibiting the MAPK/ERK pathway within the retina at this concentration.

\section{RGC counts}

Similar to our observations on RGC survival and axonal regeneration after LY294002 treatment, intravitreal injections of PD98059 significantly enhanced RGC survival (18,401 \pm 903 per retina) in $\mathrm{PN}-\mathrm{ON}$-only animals. The twofold increase was significantly higher than saline-injected $(p<0.05$; Bonferroni) and $\mathrm{PN}-\mathrm{ON}$ control ( $p<0.001$; Bonferroni) groups (Fig. $1 A$ ). Again, because the number of surviving RGCs was greater, the number of axon-regenerating RGCs also increased after PD98059 treatment $(5275 \pm 909$ per retina). This increase was not, however, significantly higher than in the saline group (Fig. $1 A)$. Note that the proportion of axon-regenerating RGCs in this group was $28.7 \%$, similar to the saline group, again suggesting that the increased number of regenerating axons was simply the result of increased overall viability of the injured RGC population.

In the presence of CNTF/CPT-cAMP, PD98059 substantially blocked the CNTF/CPT-cAMP-induced increase in RGC sur- 
A
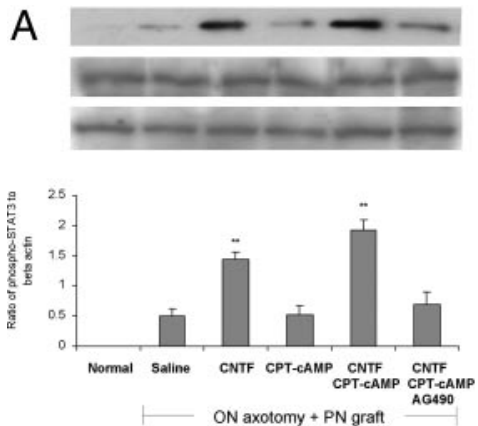

B

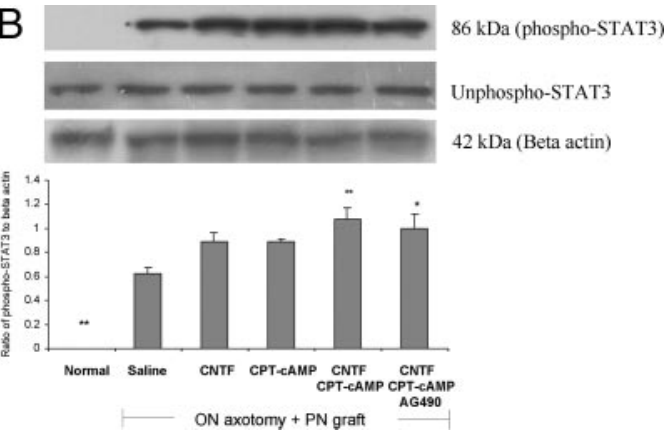

Figure 6. Western blotting study on the JAK pathway downstream product phosphorylated STAT3 $6 \mathrm{hr}(A)$ or $3 \mathrm{~d}(B)$ after various experimental interventions. The JAK pathway inhibitor AG490 substantially blocked the CNTF-induced increase in JAK pathway activity at $6 \mathrm{hr}$ but failed to exert any effect on the CNTF/CPT-CAMP-induced increase in JAK/STAT3 pathway activity $3 \mathrm{~d}$ after intravitreal injection. ${ }^{*} p<0.05,{ }^{* *} p<0.01$; Dunnett's test; comparisons were made against the saline group. Error bars represent SEM.

vival $(13,848 \pm 1679$ per retina), a value not significantly higher than the saline group (Fig. $1 B$ ). The CNTF/CPT-cAMP-induced increase in axonal regeneration was also significantly $(p<0.001)$ blocked after PD98059 treatment, but the value (4983 \pm 799 per retina), although not statistically significant, was still higher than the saline group (Fig. $1 B$ ). Similar effects on RGC survival and axonal regeneration were seen after application of PD98059 at a lower concentration $(50 \mu \mathrm{M})$ in the presence of CNTF/CPTcAMP (data not shown).

\section{JAK/STAT3 pathway in spontaneous and CNTF/cAMP- induced RGC survival and axonal regeneration \\ Western blots}

Western blot analysis revealed substantial differences in JAK/ STAT3 pathway activity at $6 \mathrm{hr}$ and $3 \mathrm{~d}$, as determined by levels of the JAK/STAT3 pathway downstream product phospho-STAT3 (Fig. 6A, B). In normal intact retinas, no JAK/STAT3 activation was seen, but activity was slightly increased $6 \mathrm{hr}$ after intravitreal injection of saline, suggesting a minor influence of the PN-ON procedure and intravitreal injection on this pathway at this early stage. However, intraocular CNTF injections significantly enhanced the level of phospho-STAT3 $6 \mathrm{hr}$ after injection $(p<$ 0.01; Dunnett's test) (Fig. 6A). These in vivo results are thus consistent with previous data showing that biological activities of CNTF are mediated by the JAK/STAT3 pathway. Although an increase was also seen after intravitreal injection of CPT-cAMP, the difference was not statistically significant (Fig. 6A).

When CNTF and CPT-cAMP were applied together, a synergistic effect on the level of phospho-STAT3 was seen. Compared with the CNTF treatment group, the level of phospho-STAT3 in the combined treatment group was significantly higher $(p<$ 0.05; Bonferroni) (Fig. 6A). These data thus suggest (1) that cAMP elevation might potentiate CNTF-induced JAK/STAT3 activity or (2) that CNTF and CPT-cAMP might act via different mechanisms to enhance JAK/STAT3 pathway activity at the early stage. The dramatic increase in phospho-STAT3 protein expression after CNTF and CPT-cAMP application was substantially blocked ( $p<0.001$; Bonferroni) by intravitreal injection of AG490 at $2 \mathrm{~mm}$ (Fig. 6A), confirming the effectiveness of this molecule in inhibiting the JAK/STAT3 pathway in our in vivo model.

Three days after the intravitreal injections, the level of phospho-STAT3 was substantially increased in saline-treated retinas $(p<0.01$; Dunnett's test). Although greater levels of phospho-STAT3 were also seen in each of the CNTF and CPT-
cAMP treatment groups at this time point, no statistical difference was seen when compared with the saline group (Fig. $6 B$ ), suggesting a slow upregulation process after the $\mathrm{PN}-\mathrm{ON}$ procedure and the eye injection. However, compared with the saline treatment group, at least an additional significant increase in the level of phospho-STAT3 was seen after combined application of CNTF and CPT-cAMP ( $p<0.01$; Dunnett's test) (Fig. $6 B$ ). In addition, AG490 treatment failed to block the JAK/STAT3 pathway at this time, because its influence on a CNTF/CPT-cAMP-induced increase in phospho-STAT3 level was minimal (Fig. $6 B)$. These data suggest (1) that the AG490 inhibitor had only temporary blocking effects and (2) that cAMP elevation had a slow but progressive influence on JAK/STAT3 pathway activity.

\section{$R G C$ counts}

As with the other two pathway inhibitors, intravitreal injection of the JAK/STAT3 inhibitor AG490 (2 mM) enhanced RGC survival $(20,640 \pm 1548$ per retina) (Fig. $1 A)$ in control PN-grafted rats. This was significantly higher than the PN-ON control $(p<$ 0.001; Bonferroni) and saline-injected $(p<0.01$; Bonferroni) groups. The treatment also increased spontaneous axonal regeneration, but not significantly, resulting in a mean number of $5446 \pm 949$ axon-regenerating RGCs per retina, a twofold increase compared with the saline group (Fig. 1A). As before, this increased axonal regeneration was likely attributable to the increased pool of surviving RGCs; the proportion of axonregenerating RGCs in the AG490 treatment group was $26.9 \%$, very similar to the saline-injected group (28.6\%).

In the presence of CNTF/CPT-cAMP, AG490 substantially blocked the CNTF/CPT-cAMP-induced increase in RGC survival (11,488 \pm 1296 per retina), a value not significantly different from the saline group (Fig. $1 B$ ). The CNTF/CPT-cAMPinduced increase in axonal regeneration was also significantly $(p<0.001$; Bonferroni) blocked after AG490 treatment $(4360 \pm$ 609 per retina), a value not significantly higher than the saline control (Fig. $1 B$ ). Note that the successful blockade of the CNTF/ CPT-cAMP-induced survival and axonal regeneration by AG490 was achieved in the absence of complete inhibition of JAK/ STAT3 signaling cascades.

\section{Lack of cross-talk between PI3K/akt, MAPK/EERK, and JAK/ STAT3 pathways after $\mathrm{PN}-\mathrm{ON}$ procedure}

Western blot results revealed that selective pharmacological inhibition of any one of these kinase pathways did not alter expression or activity in the remaining two pathways. Thus, the levels of phospho-akt and phospho-ERK1/2, phospho-akt and phosphoSTAT3, and phospho-ERK1/2 and phospho-STAT3 remained unaffected in the retina after intravitreal injections of JAK/ STAT3, MAPK/ERK, and PI3K/akt pathway blockers, respectively (Fig. $7 A-C$ ). These results indicate that the surprising increase in RGC survival after intravitreal injection of LY294002, PD98059, or AG490 was unlikely to be caused by a compensatory increase in activity in one of the other, noninhibited kinase signaling pathways. 
Changes in CNTFR $\alpha$ expression in retina after intraocular intervention CNTFR $\alpha$ mRNA expression was quantified $6 \mathrm{~d}$ after $\mathrm{ON}-\mathrm{PN}$ transplantation and $3 \mathrm{~d}$ after intraocular injection of control or pharmacological agents. The ON-PN procedure itself appeared to have little impact on the level of CNTFR $\alpha$ mRNA expression, because there was only a slight decrease in the level of CNTFR $\alpha$ mRNA in the saline group compared with normal intact animals (Fig. 8). Intraocular CNTF injection also had little effect, but intraocular injection of CPT-cAMP (0.1 mM) did increase CNTFR $\alpha$ mRNA expression, an effect that was blocked by the PKA pathway inhibitor KT5720 (Fig. 8). Note that CPT-cAMP at higher dosages (0.5 and 1 $\mathrm{mm}$ ) decreased the CNTFR $\alpha$ mRNA expression level, perhaps as a result of detrimental effects on the retinas. In fact, it was noticed that the retinas treated at these higher dosages appeared to be soft and disintegrated during the dissection procedure. Similar poor condition of the retinas after CPT-cAMP treatment at these high dosages was also observed in an ON crush model (data not shown). At the appropriate concentrations, the results do suggest, however, that cAMP analogs may increase CNTFR $\alpha$ mRNA expression in a PKA pathway-dependent manner.

\section{Discussion}

In this study, we systematically analyzed the influence of major signaling pathways (PKA, PI3K/akt, MAPK/ERK, and JAK/ STAT3) on CNTF and CAMP actions in promoting adult rat RGC viability and axonal regrowth. We showed that the CNTF/cAMPinduced enhancement of survival and axonal regeneration into PN grafts after ON injury is primarily PKA pathway dependent and involves PI3K/akt, MAPK/ERK, and JAK/STAT3 signaling pathways. In addition, upregulation of CNTFR $\alpha$ by cAMP elevation may also participate in the enhancement of RGC survival and axonal regeneration.

Importantly, PI3K/akt, MAPK/ERK, and JAK/STAT3 pathways appear to exert different biological functions under different conditions. After the $\mathrm{PN}-\mathrm{ON}$ procedure, and in the absence of exogenous CNTF/cAMP elevation, these kinases appeared to participate in the process leading to RGC death, because inhibition of any of the pathways promoted RGC survival after axotomy and PN grafting. Interestingly, PKA inhibition by itself did not influence RGC viability in this group of animals. Although there were more adult RGCs that regenerated their axons into PN grafts in the LY294002-, PD98059-, and AG490-treated groups, this increase was most likely merely a consequence of the overall increase in RGC survival. This interpretation is based on the fact that, as a proportion of viable RGCs, the proportion of axonregenerating RGCs among the LY294002, PD98059, and AG490 groups $(23.7,28.7$, and $26.9 \%$, respectively) was very similar to saline-injected controls $(28.6 \%)$ and animals injected with KT5720 (25.1\%). In comparison, combined injection of CNTF and $\mathrm{CPT} / \mathrm{cAMP}$ clearly had a specific impact on RGC axonal regeneration, because in this group, the proportion of viable RGCs that regenerated an axon was 60\% (cf. Cui et al., 2003).

The cell death data are in contrast to previous work that

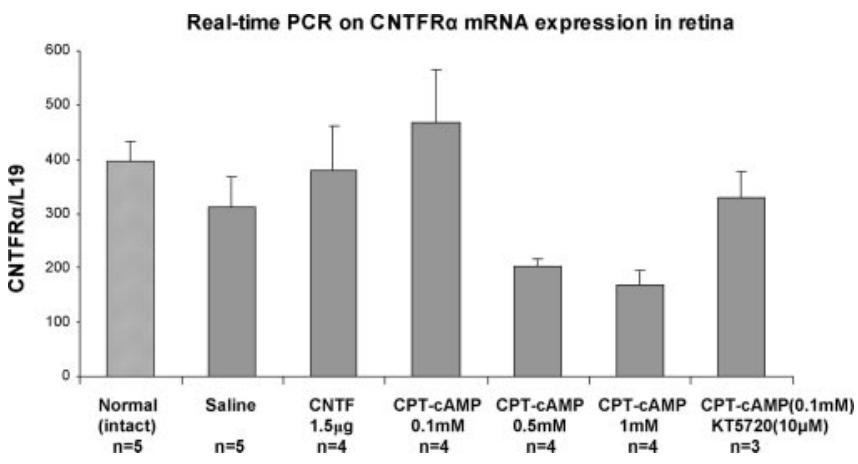

Figure 8. Real-time PCR studies showing the expression levels of CNTFR $\alpha$ against the housekeeping gene $L 19$ after various treatments. All groups received the $\mathrm{PN}-0 \mathrm{~N}$ procedure and intraocular treatment ( $3 \mathrm{~d}$ later) except the normal intact control (striped bar). CNTFR $\alpha$ expression in the retina decreased after $\mathrm{ON}$ injury and saline treatment. Intraocular injection of the CAMP analog (PT-CAMP at the appropriate concentration $(0.1 \mathrm{~mm}$ in $3 \mu \mathrm{l})$ substantially upregulated CNTFR $\alpha$ expression (nearly 50\% increase compared with the saline group), an effect that was completely blocked by the specific PKA pathway inhibitor KT5720 (10 $\mu \mathrm{m}$ in $3 \mu \mathrm{l})$. CNTF treatment $(1.5 \mu \mathrm{g})$ slightly increased the level of CNTFR $\alpha$ expression. Error bars represent SEM.

showed that PI3K/akt and MAPK/ERK are the major signaling executors for neuronal survival (Crowder and Freeman, 1999; Datta et al., 1999; Klocker et al.; 2000; Brunet et al., 2001; Rong et al., 2003). However, in renal epithelial cells, the PI3K/akt pathway inhibitor LY294002 increased bcl-2 protein and inhibited apoptosis (Carbott et al., 2002), and in cardiomyocytes, PI3K accelerated necrotic cell death during hypoxia (Aki et al., 2001). Furthermore, the MAPK/ERK pathway inhibitor PD98059 has been shown to be neuroprotective after focal cerebral ischemia (Alessandrini et al., 1999). In the absence of CNTF/cAMP after ON-PN transplantation, the PI3K/akt pathway inhibitor LY294002 may protect RGCs by enhancing the level of bcl-2, an important survival-promoting gene for neurons (Bähr, 2000; Nuydens et al., 2000; Yuan and Yankner, 2000), including RGCs (Huang et al., 2003; Isenmann et al., 2003). ERK has been shown to phosphorylate synapsin I, a major phosphoprotein found in nerve terminals (Jovanovic et al., 1996; Matsubara et al., 1996). Synapsin I maintains synaptic vesicles, and phosphorylation of 
this protein may lead to the dissociation of the vesicles, resulting in the release of excitotoxic amino acids such as glutamate (Alessandrini et al., 1999). Thus, the MAPK/ERK pathway inhibitor PD98059 may protect RGCs by preventing excitotoxic amino acid release. It is also possible that the increased RGC survival is achieved by enhanced c-fos signal after PD98059 treatment, because increased c-fos signal, known to be associated with regulation of excitability and neuronal survival (Zhang et al., 2002) including RGCs (Oshitari et al., 2002), was seen in the cortex of PD98059-treated animals (Alessandrini et al., 1999).

Although it has been reported previously in other systems that MAPK/ERK and PI3K negatively regulate STAT-transcriptional activities (Krasilnikov et al., 2003) that and stimulation of the MAPK pathway inhibits STAT activation, perhaps via suppressor of cytokine signaling (Terstegen et al., 2000), the observed increases in RGC survival are unlikely to be attributable to crosstalk between PI3K/akt, MAPK/ERK, and JAK/STAT3 pathways, because we failed to detect any influence of inhibition of one particular pathway on the activity of the other two pathways. Interestingly, the MAPK/ERK signaling cascade has been shown recently to act in an antagonistic manner in sympathetic neurons, and the MAPK/ERK pathway inhibitor PD98059 enhances dendritic growth of sympathetic neurons in vitro (Kim et al., 2004).

It is also necessary to consider the possibility that indirect action by other cellular components in the retina after PI3K/akt, MAPK/ERK, or JAK/STAT3 pathway inhibition may have contributed to the observed increases in RGC survival. Intravitreal injection of kinase inhibitors will affect RGCs situated in the innermost ganglion cell layer, but if these molecules are sufficiently permeable, they may also influence signaling in glia and other retinal neurons located in deeper retinal layers. In the presence or absence of exogenous CNTF/CPT-cAMP, the other major cell populations in the retina, such as photoreceptors, Müller cells, amacrine cells, etc., may respond differentially to the different environments. These altered responses could result in changed neurotrophic factor production, metabolism, and/or energy consumption that could directly or indirectly affect RGC survival. Macrophages are of particular interest in this regard, because we have shown recently that factors from activated macrophages in the eye promoted RGC survival and axonal regeneration (Yin et al., 2003). It is possible that inhibition of PI3K/akt, MAPK/ERK, or JAK/STAT3 pathways might lead to signaling cascades that result in macrophage activation. Finally, production of CNTF in Müller cells (Chun et al., 2000) may vary under different experimental conditions and could also have contributed to different RGC survival and axonal regeneration.

Recently, Mao et al. (2004) reported a positive link between ionotropic glutamate receptors and ERK1/2 phosphorylation. Abnormal activation of glutamate receptors can compromise cell viability via cellular cascades resulting from alterations in $\mathrm{Ca}^{2+}$ and $\mathrm{Na}^{+}$influx and $\mathrm{K}^{+}$efflux (Yu et al., 1999; Zipfel et al., 2000; Arundine and Tymianski, 2003); thus, it is possible that changes in glutamate sensitivity-signaling were also involved in PI3K/akt, MAPK/ERK, or JAK/STAT3 pathway-dependent RGC death in PN-grafted rats (Skaper et al., 2001). In fact, PI3K has been shown recently to increase calcium channel trafficking to the plasma membrane and calcium influx in dorsal root ganglion neurons (Viard et al., 2004).

After intraocular CNTF/CPT-cAMP injections, inhibition of the PI3K, MAPK/ERK, or JAK/STAT3 pathways significantly blocked the pharmacologically induced axonal regeneration of axotomized adult RGCs. In this paradigm, the data are thus more consistent with the observations that PI3K, MAPK/ERK, and
JAK/STAT3 signaling are associated with neuronal survival and axonal regeneration. The CNTF receptor is composed of an extracellular CNTF binding subunit, CNTFR $\alpha$, and two transmembrane proteins, glycoprotein 130 and leukemia inhibitory factor receptor $\beta$ (Ip et al., 1992; 1993; Davis et al., 1993). Via this receptor complex, $\mathrm{CNTF}$ activates multiple signaling pathways, including PI3K/akt, MAPK/ERK, and JAK/STAT3 signaling pathways (MacLennan et al., 2000; Alonzi et al., 2001; Dolcet et al., 2001). Activation of PI3K/akt and MAPK/ERK can result in phosphorylation (and thus inactivation) of proapoptotic Bad and activation of anti-apoptotic bcl-2 proteins (Alonzi et al., 2001; Brunet et al., 2001), both potentially working together to enhance RGC survival in this adult injury model. In addition, elevation of cAMP increases the responsiveness of purified embryonic or neonatal RGCs to a range of trophic factors (Meyer-Franke et al., 1995 ) via various mechanisms (Goldberg and Barres, 2000; Hansen et al., 2001; Reiriz et al., 2002) or membrane depolarization (Meyer-Franke et al., 1998). Greater RGC viability and improved long-term survival in vitro is obtained if cAMP is elevated in combination with a mixture of factors including BDNF, CNTF, and insulin growth factor-1. Elevation of cAMP in RGCs allows the translocation of MAPK to the nucleus in response to appropriate trophic stimulation (Meyer-Franke et al., 1998).

It is known that the response of a neurite to a given guidance or adhesion molecule can be modulated by changing cAMP levels and/or by blocking PKA (Ming et al., 1997; Song and Poo, 1999). Raised cAMP may also reduce the effect of growth-inhibitory factors on axon-regenerating adult RGCs (Cai et al., 1999; 2001). cAMP-induced activation of PKA phosphorylates and thus inhibits Rho signaling pathways (Lehmann et al., 1999). Recently, a number of studies have shown increased axonal regeneration after elevation of intracellular cAMP (Nikulina et al., 2004; Pearse et al., 2004). Inhibition of Rho pathway may be one of the mechanisms underlying cAMP elevation-induced axonal regeneration. Although we did not see increased axonal regeneration into a PN graft after elevation of cAMP level in the eye (Cui et al., 2003), enhanced axonal growth into the distal part of a crushed $\mathrm{ON}$ has been seen (our unpublished observation). This is consistent with a recent report in which intraocular injection of cAMP analog promotes axonal regeneration in the ON (Monsul et al., 2004).

Forskolin, which enhances intracellular cAMP levels, has been shown recently to increase CNTFR $\alpha$ mRNA expression in cultured neonatal olfactory ensheathing cells (Wewetzer et al., 2001). In our in vivo model, we found that elevation of cAMP also increased CNTFR $\alpha$ mRNA expression in the retina. In the presence of exogenous CNTF, the increased level of CNTFR $\alpha$ by cAMP elevation may facilitate the action of CNTF on neuronal survival and axonal regeneration.

In summary, PKA, PI3K/akt, MAPK/ERK, and JAK/STAT3 pathways are all involved in CNTF/CPT-cAMP-induced survival and axonal regeneration, with the PKA pathway appearing to be more influential. However, the exact roles of these signaling pathways vary under different conditions. In the visual system, the role of these pathways may be critically dependent on how the RGCs are injured and the nature of the conditions to which the injured RGCs are exposed (e.g., whether they are exposed to exogenous neurotrophic factors). Our data show (1) that CNTF/ CPT-cAMP-induced RGC survival and axonal regeneration were PKA, PI3K/akt, MAPK/ERK, and JAK/STAT3 pathway dependent and (2) that in the absence of CNTF/CPT-cAMP, PI3K/akt, MAPK/ERK, or JAK/STAT3, pathway inhibition resulted in increased RGC survival. The possible cellular and/or molecular 
mechanisms underlying this unexpected increase in RGC survival after intraocular kinase inhibition are currently under investigation.

\section{References}

Aki T, Mizukami Y, Oka Y, Yamaguchi K, Uemura K, Fujimiya T, Yoshida K (2001) Phosphoinositide 3-kinase accelerates necrotic cell death during hypoxia. Biochem J 358:481-487.

Alessandrini A, Namura S, Moskowitz MA, Bonventre JV (1999) MEK1 protein kinase inhibition protects against damage resulting from focal cerebral ischemia. Proc Natl Acad Sci USA 96:12866-12869.

Alessi DR, Cuenda A, Cohen P, Dudley DT, Saltiel A (1995) PD098059 is a specific inhibitor of the activation of mitogen activated protein kinase kinase in vitro and in vivo. J Biol Chem 270:27489-27494.

Alonzi T, Middleton G, Wyatt S, Buchman V, Betz UA, Muller W, Musiani P, Poli V, Davies AM (2001) Role of STAT3 and PI 3-kinase/Akt in mediating the survival actions of cytokines on sensory neurons. Mol Cell Neurosci 18:270-282.

Arundine M, Tymianski M (2003) Molecular mechanisms of calciumdependent neurodegeneration in excitotoxicity. Cell Calcium 34:325-337.

Atwal JK, Massie B, Miller FD, Kaplan DR (2000) The trkB-Shc site signals neuronal survival and local axon growth via MEK and PI3-kinase. Neuron 27:265-277.

Bähr M (2000) Live or let die-retinal ganglion cell death and survival during development and in the lesioned adult CNS. Trends Neurosci 23:483-490.

Brunet A, Datta SR, Greenberg ME (2001) Transcription-dependent and -independent control of neuronal survival by the PI3K-Akt signalling pathway. Curr Opin Neurobiol 11:297-305.

Cai D, Shen Y, De Bellard M, Tang S, Filbin MT (1999) Prior exposure to neurotrophins blocks inhibition of axonal regeneration by MAG and myelin via a cAMP-dependent mechanism. Neuron 22:89-101.

Cai D, Qiu J, Cao Z, McAtee M, Bregman BS, Filbin MT (2001) Neuronal cAMP controls the developmental loss in ability of axons to regenerate. J Neurosci 21:4731-4739.

Campos CB, Bedard PA, Linden R (2003) Selective involvement of the PI3K/PKB/Bad pathway in retinal cell death. J Neurobiol 56:171-177.

Carbott DE, Duan L, Davis MA (2002) Phosphoinositide 3-kinase inhibitor, LY294004 increases bcl-2 protein and inhibits okadaic acid-induced apoptosis in bcl-2 expressing renal epithelial cells. Apoptosis 7:69-76.

Cho EY, So KF (1987) Rate of regrowth of damaged retinal ganglion cell axons regenerating in a peripheral nerve graft in adult hamsters. Brain Res 419:369-374

Chun MH, Ju WK, Kim KY, Lee MY, Hofmann HD, Kirsch M, Oh SJ (2000) Upregulation of ciliary neurotrophic factor in reactive Muller cells in the rat retina following optic nerve transection. Brain Res 868:358-362.

Cowley S, Paterson H, Kemp P, Marshall CJ (1994) Activation of MAP kinase kinase is necessary and sufficient for PC12 differentiation and for transformation of NIH 3T3 cells. Cell 77:841-852.

Crowder RJ, Freeman RS (1999) The survival of sympathetic neurons promoted by potassium depolarization, but not by cyclic AMP, requires phosphatidylinositol 3-kinase and Akt. J Neurochem 73:466-475.

Cui Q, Lu Q, So KF, Yip HK (1999) CNTF, but not other trophic factors, promotes axonal regeneration of axotomized retinal ganglion cells in adult hamsters. Invest Ophthalmol Vis Sci 40:760-766.

Cui Q, Yip HK, Zhao RC, So KF, Harvey AR (2003) Intraocular elevation of cyclic AMP potentiates ciliary neurotrophic factor-induced regeneration of adult rat retinal ganglion cell axons. Mol Cell Neurosci 22:49-61.

Datta SR, Brunet A, Greenberg M (1999) Cellular survival: a play in three Akts. Genes Dev 13:2905-2927.

Davies SP, Reddy H, Caivano M, Cohen P (2000) Specificity and mechanism of action of some commonly used protein kinase inhibitors. Biochem J 351:95-105.

Davis S, Aldrich TH, Stahl N, Pan L, Taga T, Kishimoto T, Ip NY, Yancopoulos GD (1993) LIFR beta and gp130 as heterodimerizing signal transducers of the tripartite CNTF receptor. Science 260:1805-1808.

Desbarats J, Birge RB, Mimouni-Rongy M, Weinstein DE, Palerme JS, Newell MK (2003) Fas engagement induces neurite growth through ERK activation and p35 upregulation. Nat Cell Biol 5:118-125.

Dolcet X, Soler RM, Gould TW, Egea J, Oppenheim RW, Comella JX (2001) Cytokines promote motoneuron survival through the janus kinasedependent activation of the phosphatidylinositol 3-kinase pathway. Mol Cell Neurosci 18:619-631.
Goldberg JL, Barres BA (2000) The relationship between neuronal survival and regeneration. Annu Rev Neurosci 23:579-612.

Goldberg JL, Espinosa JS, Xu Y, Davidson N, Kovacs GT, Barres BA (2002) Retinal ganglion cells do not extend axons by default: promotion by neurotrophic signalling and electrical activity. Neuron 33:689-702.

Guillet C, Lelievre E, Plum-Favreau H, Froger J, Chabbert M, Hermann J, Benoit de Coignac A, Bonnefoy J-Y, Gascan H, Gauchat J-F, Elson G (2002) Functional active fusion protein of the novel composite cytokine CLC/soluble CNTF receptor. Eur J Biochem 269:1932-1941.

Hansen MR, Zha XM, Bok J, Green SH (2001) Multiple distinct signal pathways, including an autocrine neurotrophic mechanism, contribute to the survival-promoting effect of depolarization on spiral ganglion neurons in vitro. J Neurosci 21:2256-2267.

Hanson Jr MG, Shen S, Wiemelt AP, McMorris FA, Barres BA (1998) cAMP elevation is sufficient to promote the survival of spinal motor neurons in vitro. J Neurosci 18:7361-7371.

Huang X, Wu DY, Chen G, Manji H, Chen DF (2003) Support of retinal ganglion cell survival and axon regeneration by lithium through a Bcl-2dependent mechanism. Invest Ophthalmol Vis Sci 44:347-354.

Ip NY, Yancopoulos GD (1996) The neurotrophins and CNTF: two families of collaborative neurotrophic factors. Annu Rev Neurosci 19:491-515.

Ip NY, Nye SH, Boulton TG, Davis S, Taga T, Li Y, Birren SJ, Yasukawa K, Kishimoto T, Anderson DJ, Stahl N, Yancopoulos GD (1992) CNTF and LIF act on neuronal cells via shared signalling pathways that involve IL-6 signal transducing receptor component gp130. Cell 69:1121-1132.

Ip NY, McClain J, Barrezueta NX, Aldrich TH, Pan L, Li Y, Wiegand SJ, Friendman B, Davis S, Yancopoulos GD (1993) The alpha component of the CNTF receptor is required for signalling and defines potential CNTF targets in the adult and during development. Neuron 10:89-102.

Isenmann S, Kretz A, Cellerino A (2003) Molecular determinants of retinal ganglion cell development, survival, and regeneration. Prog Retin Eye Res 22:483-543.

Jo SA, Wang E, Benowitz LI (1999) Ciliary neurotrophic factor is an axogenesis factor for retinal ganglion cells. Neuroscience 89:579-591.

Jovanovic JN, Benfenati F, Siow YL, Sihra TS, Sanghera JS, Pelech SL, Greengard P, Czernik AJ (1996) Neurotrophins stimulate phosphorylation of synapsin I by MAP kinase and regulate synapsin I-actin interactions. Proc Natl Acad Sci USA 93:3679-3683.

Kao HT, Song HJ, Porton B, Ming GL, Hoh J, Abraham M, Czernik AJ, Pieribone VA, Poo MM, Greengard P (2002) A protein kinase A-dependent molecular switch in synapsins regulates neurite outgrowth. Nat Neurosci 5:431-437.

Kaur N, Wohlhueter AL, Halvorsen SW (2002) Activation and inactivation of signal transducers and activators of transcription by ciliary neurotrophic factor in neuroblastoma cells. Cell Signal 14:419-429.

Kim IJ, Drahushuk KM, Kim WY, Gonsiorek EA, Lein P, Andres DA, Higgins D (2004) Extracellular signal-regulated kinases regulate dendritic growth in rat sympathetic neurons. J Neurosci 24:3304-3312.

Klocker N, Kermer P, Weishaupt JH, Labes M, Ankerhold R, Bahr M (2000) Brain-derived neurotrophic factor-mediated neuroprotection of adult rat retinal ganglion cells in vivo does not exclusively depend on phosphatidylinositol-3'-kinase/protein kinase B signalling. J Neurosci 20:6962-6967.

Krasilnikov M, Ivanov VN, Dong J, Ronai Z (2003) ERK and PI3K negatively regulate STAT-transcriptional activities in human melanoma cells: implications towards sensitization to apoptosis. Oncogene 22:4092-4101.

Lehmann M, Fournier A, Selles-Navarro I, Dergham P, Sebok A, Leclerc N, Tigyi G, McKerracher L (1999) Inactivation of Rho signalling pathway promotes CNS axon regeneration. J Neurosci 19:7537-7547.

Leon S, Yin Y, Nguyen J, Irwin N, Benowitz LI (2000) Lens injury stimulates axon regeneration in the mature rat optic nerve. J Neurosci 20:4615-4626.

Li M, Wang X, Meintzer MK, Laessig T, Birnbaum MJ, Heidenreich KA (2000) Cyclic AMP promotes neuronal survival by phosphorylation of glycogen synthase kinase 3beta. Mol Cell Biol 20:9356-9363.

Lu P, Yang H, Jones LL, Filbin MT, Tuszynski MH (2004) Combinatorial therapy with neurotrophins and cAMP promotes axonal regeneration beyond sites of spinal cord injury. J Neurosci 24:6402-6409.

MacLennan AJ, Neitzel KL, Devlin BK, Garcia J, Hauptman GA, Gloaguen I, Di Marco A, Laufer R, Lee N (2000) In vivo localization and characterization of functional ciliary neurotrophic factor receptors which utilize JAK-STAT signalling. Neuroscience 99:761-772.

Mao L, Tang Q, Samdani S, Liu Z, Wang JQ (2004) Regulation of MAPK/ 
ERK phosphorylation via ionotropic receptors in cultured rat striatal neurons. Eur J Neurosci 19:1207-1216.

Matsubara M, Kusubata M, Ishiguro K, Uchida T, Titani K, Taniguchi H (1996) Site-specific phosphorylation of synapsin I by mitogen-activated protein kinase and Cdk5 and its effects on physiological functions. J Biol Chem 271:21108-21113.

Mazzoni I, Saïd FA, Aloyz R, Miller FD, Kaplan D (1999) Ras regulates sympathetic neuron survival by suppressing the p53-mediated cell death pathway. J Neurosci 19:9716-9727.

Meyer-Franke A, Kaplan MR, Pfrieger FW, Barres BA (1995) Characterization of the signalling interactions that promote the survival and growth of developing retinal ganglion cells in culture. Neuron 15:805-819.

Meyer-Franke A, Wilkinson GA, Kruttgen A, Hu M, Munro E, Hanson Jr MG, Reichardt LF, Barres BA (1998) Depolarization and cAMP elevation rapidly recruit TrkB to the plasma membrane of CNS neurons. Neuron 21:681-693.

Ming G, Song HJ, Berninger B, Holt CE, Tessier-Lavigne M, Poo MM (1997) cAMP-dependent growth cone guidance by netrin-1. Neuron 19:1225-1235.

Miura T, Tanaka S, Seichi A, Arai M, Goto T, Katagiri H, Asano T, Oda H, Mukhopadhyay G, Doherty P, Walsh FS, Crocker PR, Filbin MT (1994) A novel role for myelin-associated glycoprotein as an inhibitor of axonal regeneration. Neuron 13:757-767.

Monsul NT, Geisendorfer AR, Han PJ, Banik R, Pease ME, Skolasky Jr RL, Hoffman PN (2004) Intraocular injection of dibutyryl cyclic AMP promotes axon regeneration in rat optic nerve. Exp Neurol 186:124-133.

Namikawa K, Honma M, Abe K, Takeda M, Mansur K, Obata T, Miwa A, Okado H, Kiyama H (2000) Akt/protein kinase B prevents injuryinduced motoneuron death and accelerates axonal regeneration. J Neurosci 20:2875-2886.

Neumann S, Bradke F, Tessier-Lavigne M, Basbaum AI (2002) Regeneration of sensory axons within the injured spinal cord induced by intraganglionic cAMP elevation. Neuron 34:885-893.

Nikulina E, Tidwell JL, Dai HN, Bregman BS, Filbin MT (2004) The phosphodiesterase inhibitor rolipram delivered after a spinal cord lesion promotes axonal regeneration and functional recovery. Proc Natl Acad Sci USA 101:8786-8790.

Nishiyama M, Hoshino A, Tsai L, Henley JR, Goshima Y, Tessier-Lavigne M, Poo MM, Hong K (2003) Cyclic AMP/GMP-dependent modulation of $\mathrm{Ca}$ channels sets the polarity of nerve growth-cone turning. Nature 423:990-995.

Nuydens R, Dispersyn G, Van Den Keiboom G, de Jong M, Connors R, Ramaekers F, Borgers M, Geerts H (2000) Bcl-2 protects against apoptosis-related microtubule alterations in neuronal cells. Apoptosis 5:43-51.

Oshitari T, Dezawa M, Okada S, Takano M, Nigishi H, Horie H, Sawada H, Tokubisa T, Adachi-Usami E (2002) The role of c-fos in cell death and regeneration of retinal ganglion cells. Invest Ophthalmol Vis Sci 43:2442-2449.

Pearse DD, Pereira FC, Marcillo AE, Bates ML, Berrocal YA, Filbin MT,
Bunge MB (2004) cAMP and Schwann cells promote axon growth and functional recovery after spinal cord injury. Nat Med 10:610-616.

Peterson WM, Wang Q, Tzekova R, Wiegand SJ (2000) Ciliary neurotrophic factor and stress activate the Jak-STAT pathway in retinal neurons and glia. J Neurosci 20:4081-4090.

Qiu J, Cai D, Dai H, McAtee M, Hoffman PN, Bregman BS, Filbin MT (2002) Spinal axon regeneration induced by elevation of cyclic AMP. Neuron 34:895-903.

Reiriz J, Holm PC, Alberch J, Arenas E (2002) BMP-2 and cAMP elevation confer locus coeruleus neurons' responsiveness to multiple neurotrophic factors. J Neurobiol 50:291-304.

Rong R, Ahn JY, Huang H, Nagata E, Kalman D, Kapp JA, Tu J, Worley PF, Snyder SH, Ye K (2003) PI3 Kinase enhancer-Homer complex couples mGluR1 to PI3 kinase, preventing neuronal apoptosis. Nat Neurosci 6:1153-1161.

Rydel RE, Greene LA (1988) cAMP analogues promote survival and neurite outgrowth in cultures of rat sympathetic and sensory neurons independently of nerve growth factor. Proc Natl Acad Sci USA 85:1257-1261.

Sanchez-Margalet V, Goldfine ID, Vlahos CJ, Sung CK (1994) Role of PI3K kinase in insulin receptor signalling: studies with inhibitor LY294002. Biochem Biophys Res Commun 204:446-452.

Skaper SD, Facci L, Strijbos PJ (2001) Neuronal protein kinase signalling cascades and excitotoxic cell death. Ann NY Acad Sci 939:11-22.

Song HJ, Poo MM (1999) Signal transduction underlying growth cone guidance by diffusible factors. Curr Opin Neurobiol 9:355-363.

Terstegen L, Gatsios P, Bode JG, Schaper F, Heinrich PC, Graeve L (2000) The inhibition of interleukin-6-dependent STAT activation by mitogenactivated protein kinases depends on tyrosine 759 in the cytoplasmic tail of glycoprotein 130. J Biol Chem 275:18810-18817.

Vaillant AR, Mazzoni I, Tudan C, Boudreau M, Kaplan DR, Miller FD (1999) Depolarization and neurotrophins converge on the phosphatidylinositol 3-kinase-akt pathway to synergistically regulate neuronal survival. J Cell Biol 146:955-966.

Viard P, Butcher AJ, Halet G, Davies A, Nurngerg B, Heblich F, Dolphin AC (2004) PI3K promotes voltage-dependent calcium channel trafficking to the plasma membrane. Nat Neurosci 7:939-946.

Wewetzer K, Grothe CX, Claus P (2001) In vitro expression and regulation of ciliary neurotrophic factor and its $\alpha$ receptor subunit in neonatal rat olfactory ensheathing cells. Neurosci Lett 306:165-168.

Yin Y, Cui Q, Li Y, Irwin N, Fischer D, Harvey AR, Benowitz LI (2003) Macrophage-derived factors stimulate optic nerve regeneration. J Neurosci 23:2284-2293.

Yu SP, Yeh C, Strasser U, Tian M, Choi DW (1999) NMDA receptormediated K+ efflux and neuronal apoptosis. Science 284:336-339.

Yuan J, Yankner BA (2000) Apoptosis in the nervous system. Nature 407:802-809.

Zhang J, Zhang D, McQuade JS, Behhehani M, Tsien JZ, Xu M (2002) C-fos regulates neuronal excitability and survival. Nat Genet 30:416-420.

Zipfel GJ, Babcock DJ, Lee JM, Choi DW (2000) Neuronal apoptosis after CNS injury: the roles of glutamate and calcium. J Neurotrauma 17:857-869. 